\title{
Analisis Uji Keterbacaan Modul Fisika Berbasis STEM Education Materi Usaha dan Energi
}

\author{
Ratika Sekar Ajeng Ananingtyas \\ Universitas Nahdlatul Ulama Blitar, Inodnesia \\ Email: ratikasekar@gmail.com
}

\begin{tabular}{l}
\hline Tersedia Online di \\
\hline http://www.jurnal.unublitar.ac.id/ \\
index.php/briliant
\end{tabular}

\section{Sejarah Artikel}

Diterima pada 7 Oktober 2020

Disetuji pada 12 November 2020

Dipublikasikan pada 30

November 2020

Hal.796-801

\begin{tabular}{l}
\hline Kata Kunci: \\
\hline $\begin{array}{l}\text { Modul fisika; STEM; } \\
\text { pembelajaran }\end{array}$ \\
\hline
\end{tabular}

\begin{abstract}
Abstrak: Modul merupakan salah satu aspek penting dalam menunjang pembelajaran. Pembelajaran STEM haruslah mampu mengajak siswa untuk belajar secara mandiri, kreatif, dan berpusat pada siswa. Penelitian ini bertujuan untuk menganalisis hasil uji keterbacaan modul fisika berbasis STEM education materi usaha dan energi. Data diperoleh dari angket skala Likert yang kemudian dianalisis secara kuantitatif. Dari hasil analisis terdapat perbedaan hasil uji keterbacaan yang tidak signifikan pada dua kelompok uji sehingga dapat disimpulkan bahwa modul layak untuk digunakan sebagai bahan ajar pembelajaran STEM.
\end{abstract}

DOI:

http://dx.doi.org/10.28926/briliant .$v 3 \mathrm{i} 4.564$

\section{PENDAHULUAN}

Modul merupakan salah satu aspek penting dalam pembelajaran karena dapat digunakan sebagai pemandu pembelajaran. Modul haruslah disusun mengikuti metode pembelajaran yang digunakan, sehingga terdapat sinergi antara metode dan bahan ajar. Modul yang baik adalah modul yang disusun mengikuti kurikulum dan perkembangan ilmu pengetahuan (Alias \& Siraj, 2012). Modul juga harus disusun dengan gaya penulisan baku dan menampilkan konten yang menarik, mutakhir, serta kontekstual agar pembaca mudah memahami materi yang disajikan (Kuswandari, Sunarno, \& Supurkowo, 2013).

Pembelajaran berbasis STEM adalah pembelajaran yang mengintegrasikan empat bidang ilmu yaitu science, technology, engineering, dan mathematics dalam sistem pembelajaran yang berpusat pada siswa. Pembelajaran STEM mampu mengasah kreativitas, kemampuan berpikir kritis, dan keterampilan bekerjasama (Stohlmann, Moore, \& Roehrig, 2012). Pembelajaran STEM juga mampu melatih kemampuan memecahkan masalah melalui kegiatan berbasis proyek yang bertujuan untuk mengahasilkan solusi (Laboy-Rush, 2011).

Dalam sebuah pembelajaran dibutuhkan modul yang dapat digunakan sebagai acuan materi, kegiatan, dan asesmen untuk guru dan siswa. Modul berbasis STEM mengintegrasikan sains, matematika, teknologi, dan teknik yang dapat

796 BRILIANT: Jurnal Riset dan Konseptual

Volume 5 Nomor 4, November 2020 
menjadi katalis utama untuk pengajaran dan pembelajaran multidisiplin berbasis inkuiri. Meskipun tuntutan dan manfaat modul berbasis STEM sering disoroti, tantangan pengembangan dan implementasi modul interdisipliner kurang dibahas (Hsu, Sung, \& Sheen, 2020). Hasil penelitian lain menunjukkan bahwa modul berbasis STEM dapat mencapai peningkatan yang signifikan pada hasil belajar siswa, termasuk memperoleh pencapaian yang substansial dalam pencapaian siswa, menutup kesenjangan pencapaian, meningkatkan tingkat kelulusan sekolah menengah, dan memastikan persiapan siswa untuk sukses di perguruan tinggi dan karier (Bayles, Enszer, \& Ross, 2012). Dengan adanya modul berbasis STEM education diharapkan tujuan pendidikan dalam menyambut revolusi industri 4.0 dapat tercapai dengan maksimal (Honey, Pearson, \& Schweingruber, 2014).

Modul fisika berbasis STEM education untuk materi usaha dan energi disusun dengan memperhatikan aspek tampilan, aspek penyajian materi, dan aspek manfaat dengan mengikuti langkah-langkah PjBL-STEM. Langkah-langkah PjBLSTEM yaitu reflection, research, discovery, application, dan communication (Furi, Handayani, \& Maharani, 2018). Pada langkah-langkah PjBL-STEM terdapat bagian yang menampilkan teknologi terbaru dari aplikasi materi yang dipelajari agar siswa memiliki wawasan yang sesuai dengan perkembangan zaman. Modul fisika berbasis STEM education mengarahkan siswa untuk lebih aktif dalam pembelajaran melalui kegiatan-kegiatan yang mengasah pengetahuan dan kemampuan sains, teknologi, teknik, dan matematika yang sangat dibutuhkan di masa yang akan datang. Melalui modul berbasis STEM education guru juga dapat melakukan penilaian formatif melalui proses pembelajaran yang berpusat pada siswa. Sebagai langkah awal pengembangan modul fisika berbasis STEM education, perlu dilakukan uji keterbacaan untuk mendapatkan modul yang memenuhi aspek tampilan, aspek penyajian materi, dan aspek manfaat.

\section{METODE}

Penelitian ini merupakan penelitian kuantitatif quasi experiment dengan sampel yang diambil dengan metode purposive sample. Subjek penelitian merupakan siswa SMKN 1 Kademangan kelas X jurusan Teknik Kendaraam Ringan sebagai pengguna modul yang dibagi menjadi dua kelompok, yaitu kelompok kecil dan kelompok besar. Pemilihan kelompok didasarkan pada kemampuan siswa yang mewakili kemampuan tinggi, sedang, dan rendah dari nilai siswa di bab kinematika, sedangkan kelompok besar adalah seluruh siswa di kelas X-TKR.

Data penelitian diperoleh dari hasil isian angket uji keterbacaan modul yang menggunakan skala Likert dari dua kelompok setelah menggunakan modul fisika berbasis STEM education. Data yang diperoleh dianalisis secara kuantitatif menggunakan uji statistik inferensial yaitu independent sample t-test untuk mengetahui perbedaan hasil uji keterbacaan di dua kelompok. Hasil uji-t tersebut kemudian digunakan untuk menghasilkan kesimpulan dari penelitian ini.

\section{HASIL}

Modul fisika berbasis STEM education materi usaha dan energi dikembangkan untuk siswa SMK yang berbasis pada pembelajaran science, technology, engineering, and mathematics yang terintegrasi dalam pembelajaran. Modul ini dibuat mengikuti langkah-langkah Project Based Learning - STEM yang 
mengarahkan siswa untuk menghasilkan produk yang sesuai dengan perkembangan ilmu pengetahuan (Laboy-Rush, 2011). Langkah Project Based Learning (PjBL) STEM adalah reflection, research, discovery, application, dan communication. Modul fisika berbasis STEM education memberikan pengalaman menawarkan solusi awal, menguji solusi, dan menyimpulkan solusi dari permasalahan yang ada di sekitar siswa.

Modul fisika yang telah dikembangkan kemudian diuji keterbacaannya pada kelompok kecil dan kelompok besar siswa pengguna modul. Sampel uji keterbacaan adalah siswa jurusan teknik kendaraan ringan SMKN 1 Kademangan Kabupaten Blitar. Uji keterbacaan modul fisika dinilai melalui angket yang menggunakan skala Likert. Hasil uji keterbacaan modul fisika berbasis STEM education pada masing-masing kelompok uji dijabarkan sebagai berikut.

- Uji keterbacaan modul fisika oleh kelompok kecil

Sampel kelompok kecil uji keterbacaan modul fisika adalah siswa SMKN 1 Kademangan yang terdiri dari 6 siswa jurusan Teknik Kendaraan Ringan. Hasil uji keterbacaan modul fisika oleh kelompok kecil menunjukkan skor rata-rata sebesar 3,998 dimana skor tersebut termasuk dalam kriteria sangat baik. Skor uji keterbacaan masing-masing siswa dalam kelompok kecil ditunjukkan pada Gambar 1.

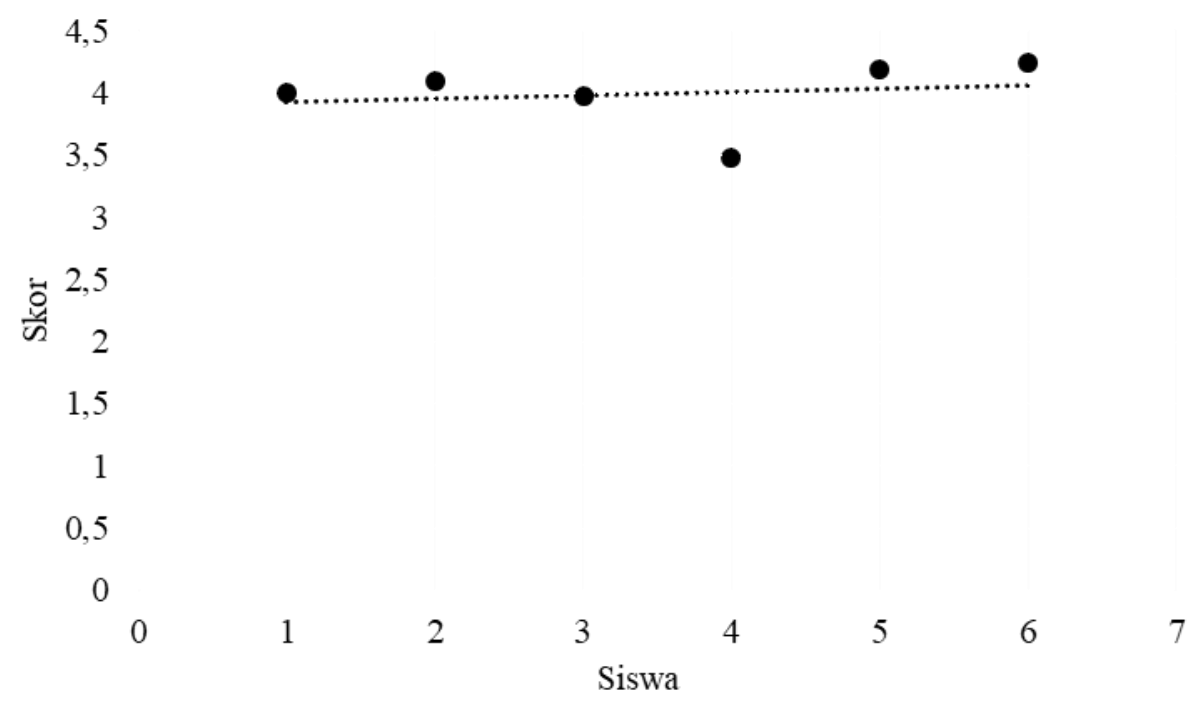

Gambar 1. Grafik skor uji keterbacaan modul fisika berbasis STEM education oleh sampel kelompok kecil

- Uji keterbacaan modul fisika oleh kelompok besar

Sampel kelompok besar uji keterbacaan modul fisika adalah siswa SMKN 1 Kademangan yang terdiri dari 30 siswa jurusan Teknik Kendaraan Ringan. Hasil uji keterbacaan modul fisika oleh kelompok kecil menunjukkan skor rata-rata sebesar 3,957 dimana skor tersebut termasuk dalam kriteria sangat baik. Skor uji keterbacaan masing-masing siswa dalam kelompok besarl ditunjukkan pada Gambar 2. 


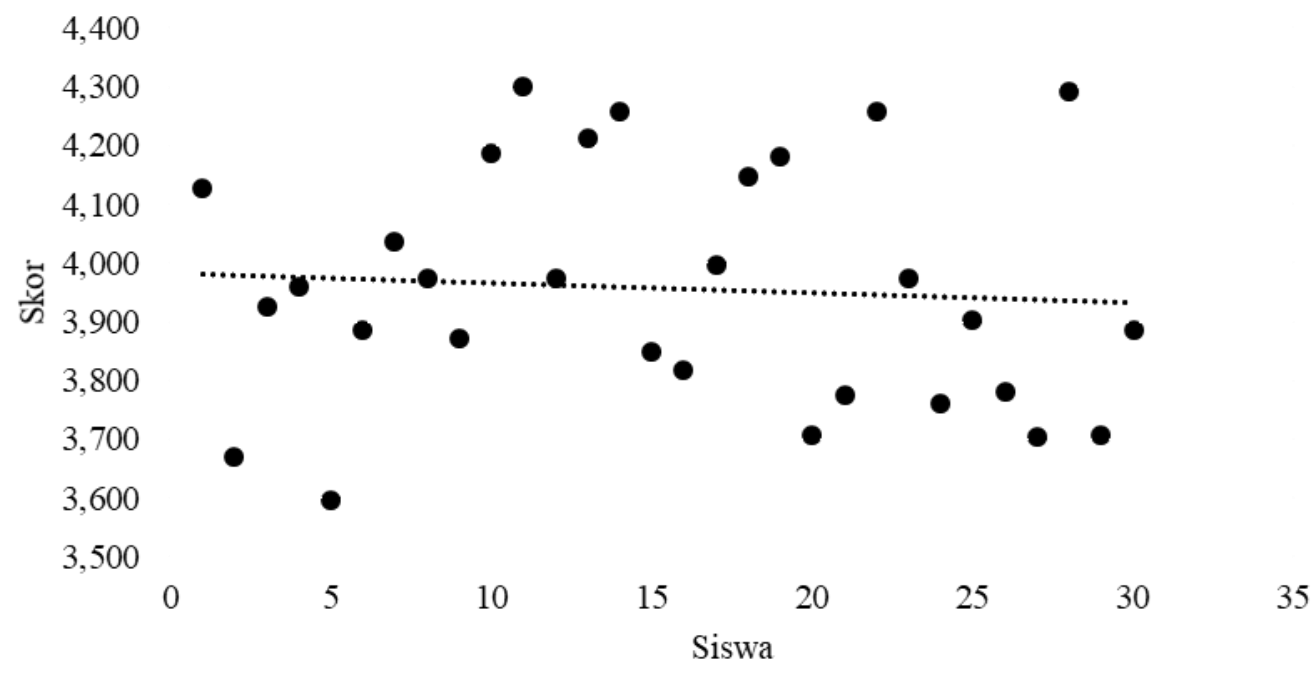

Gambar 2. Grafik skor uji keterbacaan modul fisika berbasis STEM education oleh sampel kelompok besar

\section{PEMBAHASAN}

Hasil uji keterbacaan modul fisika oleh sampel kelompok kecil dan besar dianalisis menggunakan independent sample t-test. Tujuan dari uji-t tersebut adalah untuk membandingkan skor uji keterbacaan pada kedua kelompok untuk melihat kualitas modul fisika berbasis STEM education. Namun sebelum diuji menggunakan uji-t, dilakukan analisis deskriptif untuk menampilkan grafik perbadingan skor rata-rata uji keterbacaan modul yang disajikan pada Gambar 3.

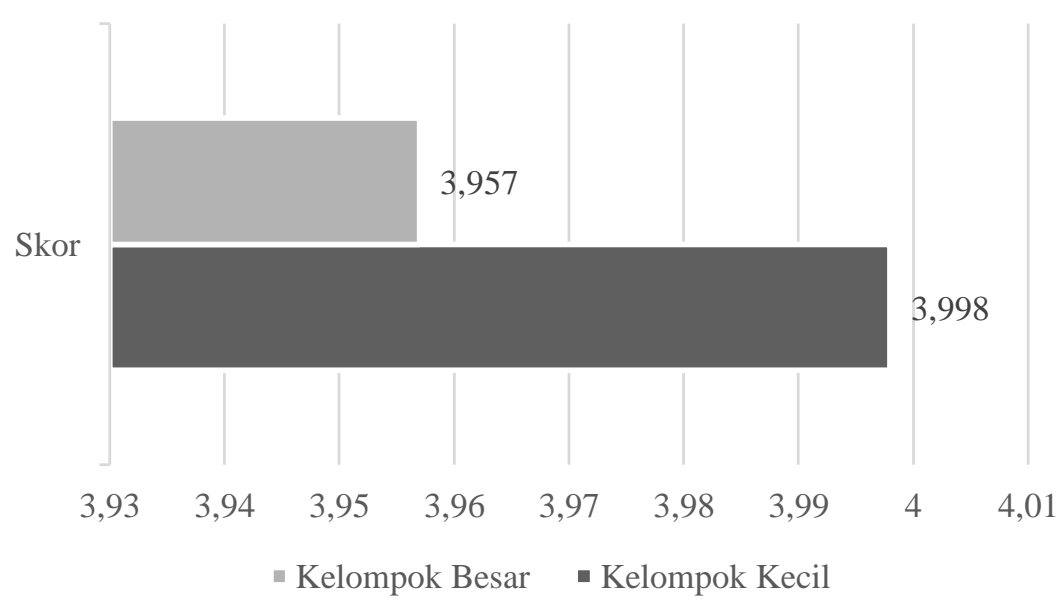

Gambar 3. Grafik perbandingan skor uji keterbacaan modul fisika berbasis STEM education oleh sampel kelompok kecil dan kelompok besar

Dari grafik di Gambar 3, tidak terdapat perbedaan skor rata-rata uji keterbacaan oleh dua kelompok sampel. Namun, perlu dilakukan uji-t sampel independen agar didapatkan kesimpulan yang lebih akurat. Hasil uji-t sampel independen dengan taraf signifikasi 5\% menghasilkan $t_{\text {hitung }}=0,419$ dan $p_{\text {hitung }}=$ 0,339 yang menunjukkan bahwa tidak terdapat perbedaan yang signifikan pada skor rata-rata uji keterbacaan antara kedua kelompok uji. Dari hasil analisis deskriptif 
dan uji-t dapat disimpulkan bahwa modul fisika berbasis STEM education layak digunakan sebagai bahan ajar pendukung pembelajaran STEM ke seluruh siswa SMKN 1 Kademangan jurusan TKR.

Modul fisika berbasis STEM education disusun dengan memperhatikan aspek tampilan, aspek penyajian materi, dan aspek manfaat dengan mengikuti langkah-langkah PjBL-STEM. Modul ini juga menampilkan teknologi terbaru dari aplikasi materi yang dipelajari agar siswa memiliki wawasan yang sesuai dengan perkembangan zaman. Hasil analisis uji keterbacaan modul fisika berbasis STEM education yang telah dikembangkan menunjukkan bahwa tampilan modul menarik, materi yang disajikan mudah dipahami, dan informasi yang disampaikan bermanfaat bagi pengguna modul. Keterbacaan modul bagi pengguna sangat perlu diperhatikan karena dapat mempengaruhi pemahaman pengguna modul terhadap materi yang disajikan. Jika modul mudah dipahami dari segi bahasa, tampilan, materi, dan manfaat maka modul dapat menunjang keberhasilan pembelajaran (Alias, Siraj, DeWitt, Attaran, \& Nordin, 2013). Selain itu, sebagai salah satu aspek penting dalam pembelajaran, modul harus mampu menunjang peningkatan pengetahuan dan keterampilan siswa dalam menghadapi tantangan di masa depan (Egarievwe, 2015).

\section{KESIMPULAN}

Dari hasil penelitian dapat disimpulkan bahwa modul fisika berbasis STEM education layak digunakan sebagai bahan ajar pendukung pembelajaran STEM pada seluruh siswa jurusan TKR SMKN 1 Kademangan Kabupaten Blitar.

\section{SARAN}

Dari kesimpulan penelitian yang menunjukkan kelayakan modul fisika berbasis STEM education, diperlukan adanya penelitian lanjutan untuk menguji keefektifan modul tersebut dalam menunjang pembelajaran STEM sebagai bahan ajar.

\section{DAFTAR RUJUKAN}

Alias, N., \& Siraj, S. (2012). Design and development of physics module based on learning style and appropriate technology by employing Isman instructional design model. Turkish Online Journal of Educational Technology.

Alias, N., Siraj, S., DeWitt, D., Attaran, M., \& Nordin, A. (2013). Evaluation on the Usability of Physics Module in a Secondary School in Malaysia: Students' Retrospective. Malaysia Online Journal of Educational Techology.

Bayles, T. M., Enszer, J. A., \& Ross, J. M. (2012). Incorporating engineering design into high school STEM initiatives. ASEE Annual Conference and Exposition, Conference Proceedings. https://doi.org/10.18260/1-2--21517

Egarievwe, S. U. (2015). Vertical Education Enhancement - A Model for Enhancing STEM Education and Research. Procedia - Social and Behavioral Sciences, 177(July 2014), 336-344. https://doi.org/10.1016/j.sbspro.2015.02.354

Furi, L. M. I., Handayani2, S., \& Maharani, S. (2018). Eksperimen Model Pembelajaran Project Based Learning Dan Project Based Learning Terintegrasi Stem Untuk Meningkatkan. Jurnal Penelitian Pendidikan.

Honey, M., Pearson, G., \& Schweingruber, H. (2014). STEM Integration in K- 12 
Education Status, Prospects, and an Agenda for Research.

Hsu, S., Sung, C. C., \& Sheen, H. J. (2020). Developing an interdisciplinary biosensor STEM module for secondary school teachers: An exploratory study. Voprosy Obrazovaniya. https://doi.org/10.17323/1814-9545-2020-2-230-251

Kuswandari, M., Sunarno, W., \& Supurkowo. (2013). Pengembangan Bahan Ajar Fisika SMA dengan Pendekatan Kontekstual pada Materi Pengukuran Besaran Fisika. Jurnal Pendidikan Fisika.

Laboy-Rush, D. (2011). Integrated STEM Education through Project-Based Learning. Learning.Com.

Stohlmann, M., Moore, T., \& Roehrig, G. (2012). Considerations for Teaching Integrated STEM Education. Journal of Pre-College Engineering Education Research. https://doi.org/10.5703/1288284314653 